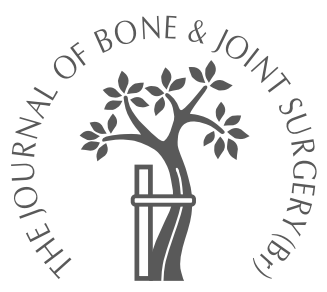
A. W. Blom,
J. L. Cunningham,
G. Hughes,
T. J. Lawes,
N. Smith,
G. Blunn,
I. D. Learmonth,
A. E. Goodship
From the University
of Bristol and
University College
London, England

A. W. Blom, PhD, FRCS ( $\mathrm{Tr}$

\& Orth), Consultant

J. L. Cunningham, PhD,

Reader

I. D. Learmonth, FRCS,

Professor

Department of Orthopaedic

Surgery, Level 5, Bristol

Royal Infirmary,

Marlborough Street, Bristol

BS2 8HW, UK.

G. Hughes, Research

Technician

T. J. Lawes,

BE(MechHons), Research

Scientist

N. Smith, PhD, Research

Scientist

G. Blunn, BSc, PhD,

Professor

A. E. Goodship, BVSc,

MRCVS, PhD, Professor

Royal Veterinary College and

Institute of Orthopaedics and

Musculoskeletal Science,

University College London,

Hawkshead Lane, North

Mymms, Hatfield, Herts AL9

7TA, UK.

Correspondence should be sent to $\mathrm{Mr} \mathrm{A}$. W. Blom;

e-mail: blocat@msn.com

(C)2005 British Editorial

Society of Bone and

Joint Surgery

doi:10.1302/0301-620X.87B3.

14337

$J$ Bone Joint Surg [Br]

2005;87-B:421-5.

Received 20 March 2003,

Accepted after revision

2 July 2004

\title{
The compatibility of ceramic bone graft substitutes as allograft extenders for use in impaction grafting of the femur
}

This study investigates the use of porous biphasic ceramics as graft extenders in impaction grafting of the femur during revision hip surgery.

Impaction grafting of the femur was performed in four groups of sheep. Group one received pure allograft, group two $\mathbf{5 0 \%}$ allograft and $\mathbf{5 0} \%$ BoneSave, group three $\mathbf{5 0} \%$ allograft and $\mathbf{5 0} \%$ BoneSave type 2 and group four $10 \%$ allograft and $\mathbf{9 0 \%}$ BoneSave as the graft material. Function was assessed using an index of pre- and post-operative peak vertical ground reaction force ratios. Changes in bone mineral density were measured by dual energy $X$ ray absorptiometry (DEXA) scanning. Loosening and subsidence were assessed radiographically and by histological examination of the explanted specimens.

There was no statistically significant difference between the four groups after 18 months of unrestricted functional loading for all outcome measures.

The restoration of bone stock is the greatest challenge in revision hip surgery. It may be achieved using impaction grafting with morsellised allograft from donor femoral heads. ${ }^{1,2}$

The problems of using allograft in impaction grafting include cost, availability, ${ }^{3-6}$ infection, ${ }^{7-}$ ${ }^{10}$ antigenicity, reproducibility ${ }^{11}$ and stability. Increasing numbers of revision arthroplasty procedures, and reduced availability of allograft, require alternative strategies to accommodate patient needs. The current solutions will not be sustainable in the future for various reasons. Xenograft and collagen matrix substances can cause infection or invoke antigenicity. ${ }^{12,13}$ Glass ionomers are non-resorbable and non-porous thereby preventing complete restitution of normal bone morphology. ${ }^{14}$ However, these materials are osteoconductive and have been used experimentally. ${ }^{15}$ In contrast, calcium sulphate resorbs very quickly and thus does not provide adequate mechanical stability before new bone formation occurs. ${ }^{16,17}$

One strategy is to extend the limited supply of allograft by using a proportion of synthetic bone graft substitute. The synthetic and allograft mixtures must provide initial functional stability. They should provide biocompatability, bone ingrowth and be resorbable, allowing replacement with host bone.

Hydroxyapatite and tricalcium phosphate ceramics have been shown to be capable of osseointegration $^{18}$ but concerns have been raised as to their ability to maintain their structural integrity under load. ${ }^{19}$ Blom et $\mathrm{al}^{20}$ have demonstrated that a porous biphasic ceramic allograft substitute (BoneSave, Stryker Howmedica Osteonics, Limerick, Ireland) is consistently more stable than allograft when used in impaction grafting in a femoral in vitro model.

In this study we hypothesise that allograft can be extended using different biphasic ceramic bone substitutes to provide biological and functional compatibility similar to that of pure allograft in an ovine hemiarthroplasty model.

\section{Materials and Methods}

Twenty skeletally mature Welsh mule ewes (body-weight 47 to $76 \mathrm{~kg}$ ) underwent right unilateral hemiarthroplasty. Pre-medication comprised $0.1 \mathrm{mg} / \mathrm{kg}$ IM xylazine (Rompun, Bayer PLC, Bury St Edmunds, UK) and the prophylactic antibiotic sodium cefalexin $1 \mathrm{mg} /$ $18 \mathrm{~kg}$ (Ceporex, Schering-Plough, Welwyn Garden City, UK).

Anaesthesia was induced using $2.5 \mathrm{mg}$ Midazolam (Hypnovel, Roche, Welwyn Garden City, UK) and $2 \mathrm{mg} / \mathrm{kg}$ ketamine hydrochloride (Ketaset, Fort Dodge Animal Health Limited, Southampton, UK) and maintained after intubation with halothane, oxygen and nitrous oxide. Post-operative analgesia was provided using $0.6 \mathrm{mg}$ buprenorphine (Temgesic, Schering-Plough) twice daily. 
A craniolateral approach was used and all cancellous bone was removed from the proximal femur. Femoral impaction grafting was performed with a custom designed, highly polished, double-tapered, stainless steel, cemented stem and antibiotic impregnated cement.

The sheep were allocated randomly to four groups each of five ewes. Group one received pure allograft, group two $50 \%$ allograft and 50\% BoneSave (Stryker Howmedica Osteonics), group three 50\% allograft and 50\% BoneSave type 2 (Stryker Howmedica Osteonics) and group four $10 \%$ allograft and $90 \%$ BoneSave. BoneSave and BoneSave type 2 are both porous biphasic ceramics. BoneSave is $20 \%$ hydroxyapatite and $80 \%$ tricalcium phosphate. BoneSave type 2 is $80 \%$ hydroxyapatite and $20 \%$ tricalcium phosphate. All allograft was cancellous bone only obtained from humeral heads harvested from adult Welsh mule sheep and sterilised by irradiation (2.5 Gy by fixed source irradiation, Isotron Ltd, Swindon, UK), frozen and stored at $-70^{\circ} \mathrm{C}$.

In vivo assessment. Assessments were made pre-operatively and at 1, 2, 4, 6, 12 and 18 months after the operation.

Peak ground reaction forces. The sheep were walked over a piezo-electric force plate (Kistler Instruments AG, Winterthur, Switzerland) in a walkway. Twelve readings of peak ground reaction forces were taken from each hind limb. The sheep were weighed on the same piezo-electric force plate and forces normalised to body-weight.

Radiography. Craniocaudal radiographs were taken using a portable x-ray unit (PLH Medical Ltd, Watford, UK). Under general anaesthetic, the sheep were placed in the left lateral position with the right hip fully extended and abducted by $30^{\circ}$. The plate was positioned dorsal to the hip with the source ventral using standardised distances and exposure. Radiographs were assessed on a ten-point scoring system for signs of loosening, endosteal bone lysis and graft resorption. The femoral shaft in each radiograph was divided into five regions of interest based on Gruen zones ${ }^{21}$ as described below for DEXA (dual energy X ray absorptiometry) analysis. The radiographs were examined by the same blinded observer $(\mathrm{AB})$. Each region of interest was scored out of two. One point was deducted if lucent lines thicker than $2 \mathrm{~mm}$ and longer than $4 \mathrm{~mm}$ were visible between either the cement and the graft, or the cortex and the graft. Two points were deducted if there was endosteal scalloping (representing loss of host bone). Two points were deducted for any evidence of graft voids (representing resorption of graft without neo-ossification). Radiographs for each animal were analysed in a chronological series so that changes over time would be evident.

$D E X A$ scanning. Under general anaesthetic, the sheep were scanned in an inclined supine position in a specially constructed frame designed to hold the hip flexed at $30^{\circ}$ and neutral with regard to abduction/adduction and rotation. A soft-tissue attenuator was placed over the right hip. The scans were analysed to determine the bone mineral density in defined regions of interest.
We designated five regions of interest based on Gruen ${ }^{21}$ zones: region 1, the lateral aspect of the proximal femur from the level of the femoral neck resection to $2.5 \mathrm{~cm}$ distally; region 2, the lateral aspect of the proximal femur from $2.5 \mathrm{~cm}$ to $5 \mathrm{~cm}$ from the level of the femoral neck resection; region 3, the lateral and medial aspect of the proximal femur from $5 \mathrm{~cm}$ to $6 \mathrm{~cm}$ from the level of the femoral neck resection $(5 \mathrm{~cm}$ from the femoral neck resection corresponds with the level of the tip of the prosthesis); region 4 , the medial aspect of the proximal femur from 2.5 $\mathrm{cm}$ to $5 \mathrm{~cm}$ from the level of the femoral neck resection; and region 5 , the medial aspect of the proximal femur from the level of the femoral neck resection to $2.5 \mathrm{~cm}$ distally.

The DEXA scans were analysed using a Hologic QDR1000/W system (Hologic, Bedford, Massachusetts). The data package subtracted soft tissue and metal from the regions of interest, measured the area in each region $\left(\mathrm{cm}^{2}\right)$ and measured the bone mineral content (grams). The bone mineral density in each area was then calculated (gram/ $\mathrm{cm}^{2}$ ).

In order to establish reproducibility a single sheep was scanned seven times. Between each scan, the sheep was removed from the scanning table and the frame dismantled and removed.

Post-mortem examination of retrieved specimens. The

sheep were killed at 22 months under general anaesthetic with barbiturate overdose, and the femora harvested. The explanted specimens were examined manually for gross loosening of the prosthesis.

Transverse slits alternately penetrating the medial and lateral cortex of the specimens were made every $2 \mathrm{~cm}$ using a diamond-edged EXAKT band saw (EXAKT, Hamburg, Germany). These slits aided infiltration of the fixative, dehydrating and embedding agents. The femur was fixed in formalin buffered with sodium cacodylate at $\mathrm{pH} 7.3$ before being dehydrated in alcohol followed by infiltration and embedding in LR White methacrylate resin (London Resin Co Ltd, Berks, UK). Using the band saw, transverse slices measuring $5 \mathrm{~mm}$ thick were taken through the implant and the femur at the levels of the tip, mid and proximal stem. These slices were radiographed. From these slices thinner sections measuring between 50 and $80 \mu \mathrm{m}$ thick were made, followed by grinding and polishing on an EXACT grinding machine. Sections were stained with toluidine blue followed by paragon before being viewed by light microscopy.

Analysis of data. The results from the four groups were compared by analysis of variance (ANOVA).

\section{Results}

Peak ground reaction forces. The mean peak ground reaction force ratio and standard deviations of the operated limb to contralateral control are shown as a function of time in Figure 1. Post-operatively the peak ground reaction forces became lower in all four groups and levelled out without returning to their pre-operative level. ANOVA 


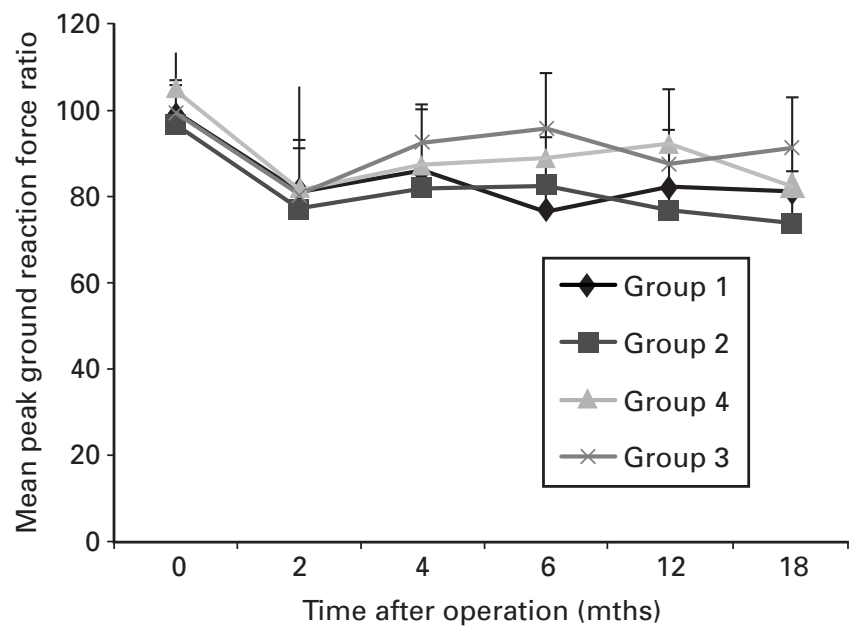

Fig. 1

Mean peak ground reaction force ratio and standard deviation of operated limb to contralateral as a function of post-operative time.

Table I. Mean radiographic scores with $\mathrm{p}$ values from ANOVA

\begin{tabular}{lllllll}
\hline & \multicolumn{7}{l}{ Month } & & & & & \\
\cline { 2 - 7 } Group & $\mathbf{1}$ & $\mathbf{2}$ & $\mathbf{4}$ & $\mathbf{6}$ & $\mathbf{1 2}$ & $\mathbf{1 8}$ \\
\hline 1 & 10 & 9.4 & 9 & 9 & 8.8 & 8.8 \\
2 & 10 & 9.4 & 9.4 & 9 & 7.8 & 7.8 \\
3 & 9.8 & 9.4 & 9.2 & 8.8 & 8.6 & 8.6 \\
4 & 10 & 9.6 & 9.6 & 9.4 & 9 & 9 \\
p value & 0.426 & 0.97 & 0.689 & 0.776 & 0.461 & 0.461 \\
\hline
\end{tabular}

showed no statistically significant differences in functional weight-bearing between the four groups at each time point. Radiography. The mean radiographic scores are outlined in Table I. There were no significant differences in scores between groups at any time point. At 18 months group three $(50 \%$ BoneSave type $2 / 50 \%$ allograft $)$ had a median score of eight, while the three other groups had a median score of nine. Trabecular formation was evident on two of the radiographs of the specimens from the sheep in group one (Fig. 2), but not from any sheep which received either BoneSave or BoneSave type 2, where the ceramic granules were still clearly visible within new bone formation on radiographs at 22 months (Fig. 3).

DEXA scanning. The coefficient of variation as a function of region ranged from $3 \%$ to $8 \%$ (Table II). Bone mineral density changes over time in the five regions of interest did not show statistically significant differences at any time point with ANOVA. An example in region 4 is shown in Figure 4. Clinical examination of retrieved specimens. Of the 20 specimens 16 were well fixed. One specimen from group one and one specimen from group two were loose and could be removed from their cement mantles with ease. One specimen from group two and one specimen from

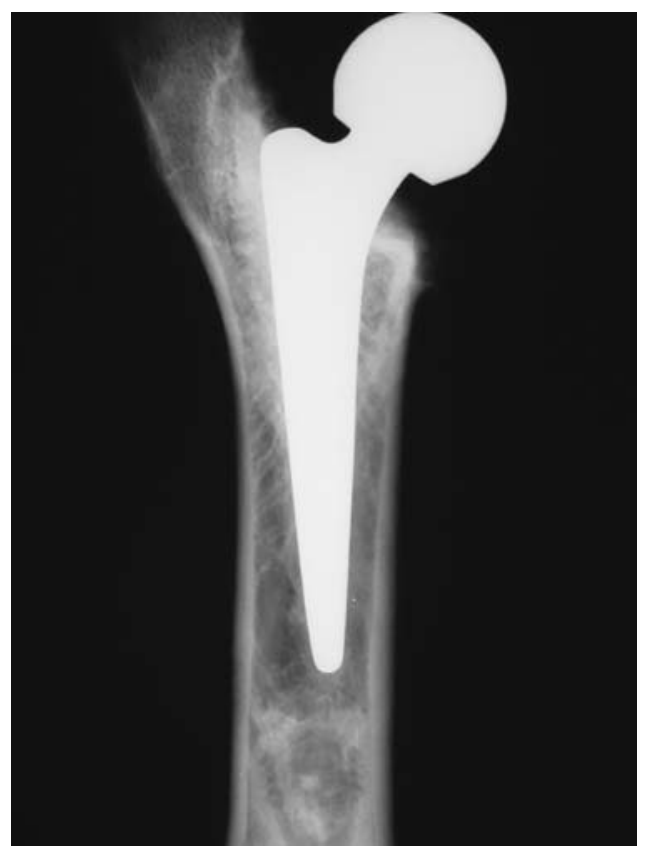

Fig. 2

Craniocaudal radiograph from the allograft group (group one) showing remodelling with trabecular formation at 22 months.

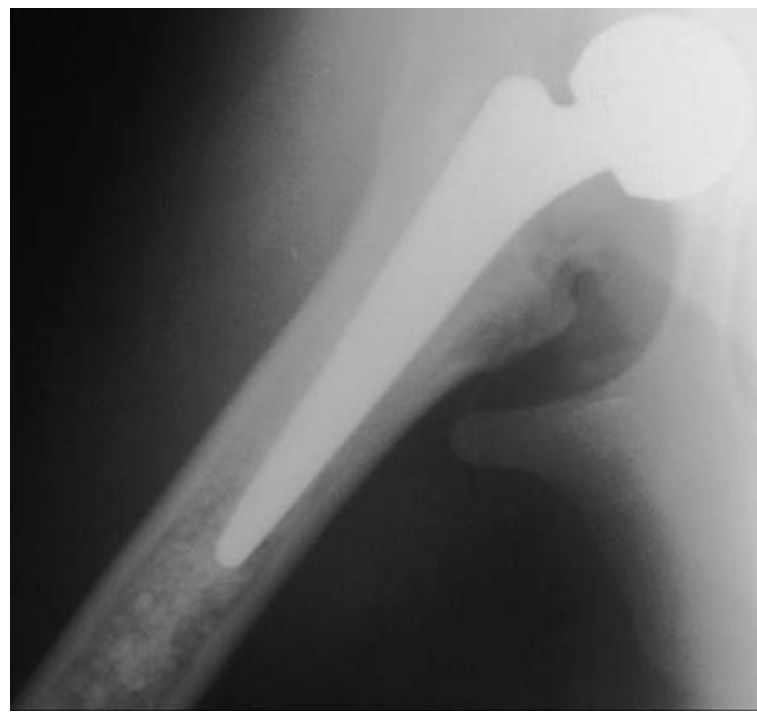

Fig. 3

Radiograph showing persistent BoneSave granules within new bone formation.

group three were rotationally unstable, with an excursion of $10^{\circ}$ and $20^{\circ}$ respectively, but could not be removed from their cement mantle. All four of these sheep had radiographic signs of loosening. They also had peak ground reaction forces at 18 months that were more than two standard deviations below their pre-operative means. 
Table II. Results of reproducibility of DEXA $\left(\mathrm{g} / \mathrm{cm}^{2}\right)$

\begin{tabular}{llllll}
\hline & Region 1 & Region 2 & Region 3 & Region 4 & Region 5 \\
\hline Mean & 0.805 & 1.214 & 1.644 & 1.120 & 1.260 \\
Standard deviation & 0.063 & 0.040 & 0.069 & 0.052 & 0.100 \\
Coefficient of variance & 0.078 & 0.033 & 0.042 & 0.046 & 0.079 \\
\hline
\end{tabular}

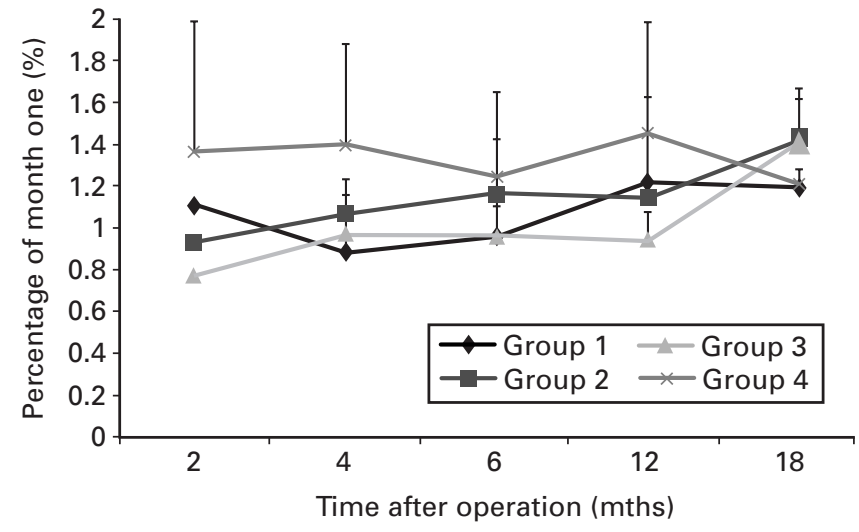

Fig. 4

Mean bone mineral density as a function of post-operative time for region 4.

Histological assessment. Transverse sections at a level halfway down the prosthesis, using both micro-CT and light microscopy, showed good bone ingrowth in all groups. No differences were seen between groups. New bone formed around the graft particles in all graft types (Fig. 5). At high power there was evidence of the synthetic ceramic particles

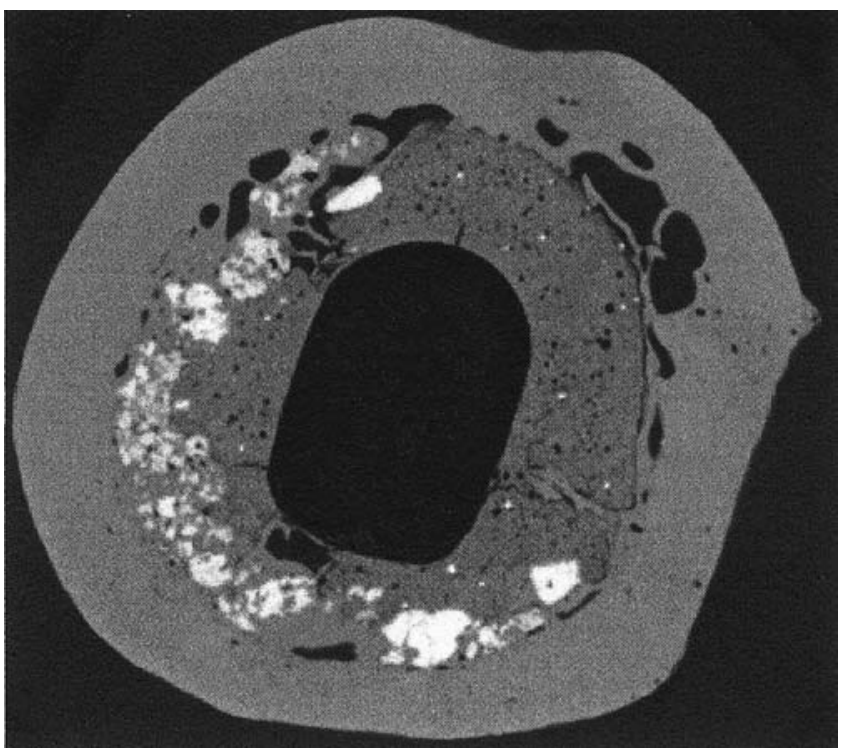

Fig. 5 a breaking down with bone ingrowth around and within the degrading granules (Fig. 6).

\section{Discussion}

The ovine hip is a good model for revision hip arthroplasty as it resembles the human clinical situation with a paucity of cancellous bone, wide medullary cavity and a smooth endosteal cavity. It allows monitoring of functional as well as biological parameters. The hip forces in the sheep correlate well with those in the human in both relative magnitude and direction ${ }^{22}$ and thus functional loading of the graft composite would be similar to that encountered in the human clinical setting. A hemiarthroplasty model avoids many of the confounding variables introduced by an acetabular prosthesis thereby simplifying the model.

There was no significant difference in functional outcome (as measured by peak ground reaction forces) or bone mineral density in the various regions of interest between the groups. Within the groups, there were no significant changes over time in bone mineral density in the various regions of interest.

Radiographic changes of endosteal scalloping as well as low peak ground reaction forces were indicators of loosening of the prosthesis, which occurred in a few sheep with

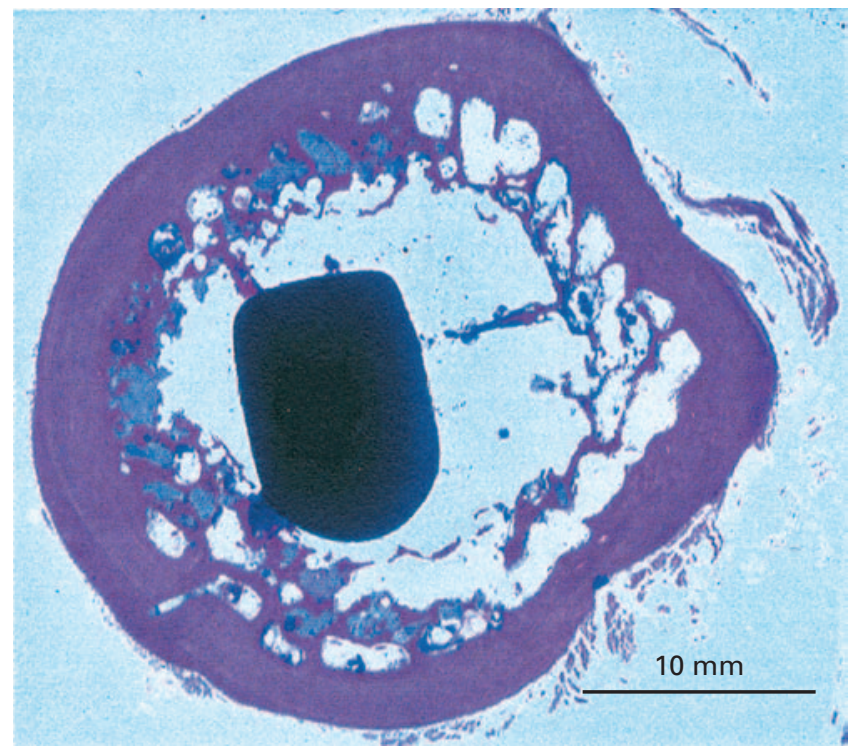

Fig. $5 b$

Figure $5 \mathrm{a}-$ Micro-CT transverse scan of a section halfway down the prosthesis ( $16 \mathrm{~mm}$ staining). Figure $5 \mathrm{~b}-$ An undecalcified section (paragon staining, $\times 2.2$. 


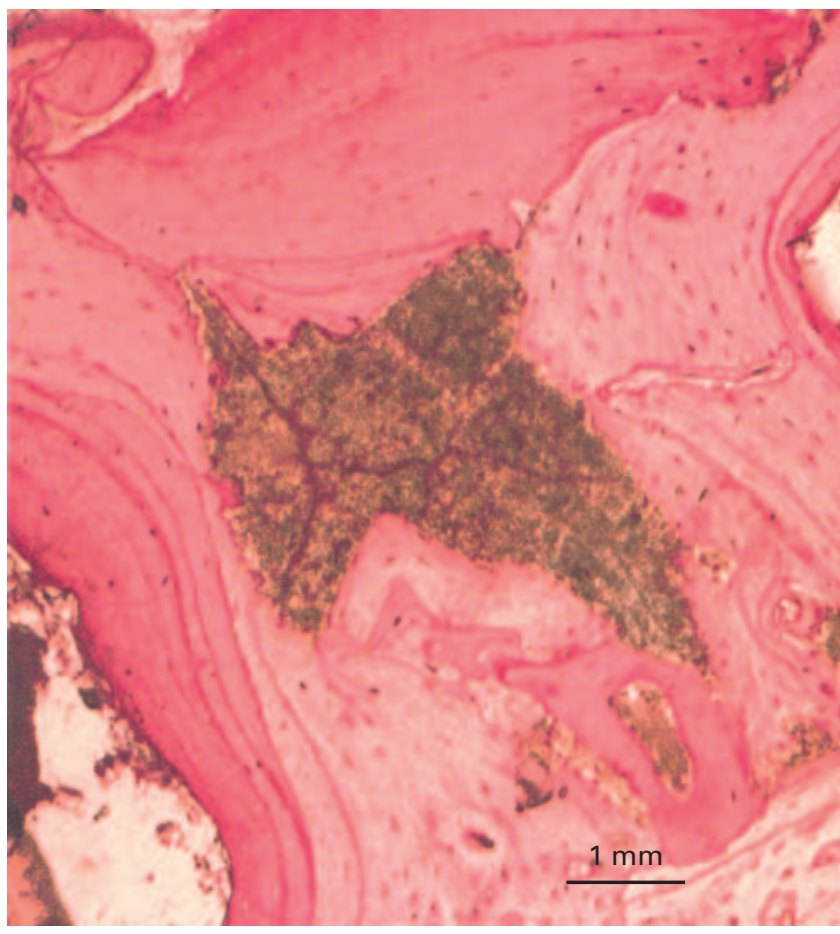

Fig. 6

High-power photomicrograph to show new bone formation within the graft and around degrading ceramic synthetic graft particles $(x 10.2)$

pure allograft and both 50/50 mixtures of ceramic and allograft, but not with the mixture of $90 \%$ BoneSave and $10 \%$ allograft.

Restoration of trabeculae within the graft was seen in the radiographs of two specimens of pure allograft, but not in those of specimens from any of the groups containing mixtures of BoneSave and allograft. The high radiodensity of the graft and persistence at 18 months may have obscured a radiological appearance of ordered neo-trabecularisation. At 18 months, the granules of BoneSave and BoneSave type 2 were still clearly visible radiologically. The persistence of these granules may help maintain composite stability. Previous studies have shown that tricalcium phosphate ceramics are rapidly resorbed when implanted in animals. ${ }^{23,24}$ This was not the case in this study, probably due to the high crystallinity $(>80 \%)$ of the synthetic materials.

The mixtures of allograft and BoneSave performed as well as pure allograft in impaction grafting of the femur in all outcome measures. The success of the $90 \%$ mixture of synthetic graft has significant clinical implications in terms of allograft savings.
The authors would like to thank the Royal College of Surgeons and Stryker Howmedica for their financial contribution to this project.

No other benefits in any form have been received from a commercial party related directly or indirectly to the subject of this article.

\section{References}

1. Gie GA, Linder L, Ling RSM, et al. Impacted cancellous allografts and cement for revision total hip arthroplasty. J Bone Joint Surg [Br] 1993;75-B:14-21.

2. Schreurs BW, Slooff TJ, Buma P, Gardeniers JW, Huiskes R. Acetabular reconstruction and impacted morsellised cancellous bone graft and cement. J Bone Joint Surg [Br] 1998;80-B:391-5.

3. Gavin S, Kenicer M, Teo P, Cresswell J, Foster K. Total elective hip and knee joint replacement: a comparative assessment. Scottish Needs Assessment Programme SNAP, 1993.

4. Galea G, Lumley S. Scottish National Blood Transfusion Service 1994/95: tissue banking services: the "What" Phase. Scottish National Blood Transfusion Service, 1995.

5. Madhok R, Lewellen DG, Wallrichs SL, et al. Trends in the utilization of primary total hip arthroplasty, 1969 through 1990: a population based study in Olmsted County, Minnesota. Mayo Clin Proc 1993;68:11-18

6. Galea G, Kopman D, Graham BJM. Supply and demand of bone allograft for revision hip surgery in Scotland. J Bone Joint Surg [Br] 1998;80-B:595-9.

7. Huo MH, Friedlander GE, Salvati EA. Bone graft and total hip arthroplasty: a review. J Arthroplasty 1992;7:109-20.

8. Simonds RJ, Holmberg SD, Hurwitz RL, et al. Transmission of human immunodeficiency virus type I from a seronegative organ and tissue donor. N Engl J Med 1992;326:726-32.

9. Buck B, Malinin T, Brown M. Bone transplantation and human immunodeficiency virus: an estimated risk of acquired immunodeficiency syndrome (AIDS). Clin Orthop 1989;240:129-36.

10. Lord CF, Gebhardt MC, Tomford WW, Mankin HJ. Infection in bone allografts: incidence, nature, and treatment. J Bone Joint Surg [Am] 1988;70-A:369-76.

11. Eldridge JDJ, Smith EJ, Hubble MJ, Whitehouse SL, Learmonth ID. Massive subsidence following femoral impaction grafting. J Arthroplasty 1997;12:535-40.

12. Chapman M, Bucholz R, Cornell C. Treatment of acute fractures with a collagencalcium phosphate graft material. J Bone Joint Surg [Am] 1997;79-A:495-502.

13. Begley C, Doherty M, Mollan R, Wilson D. Comparative study of the osseoinductive properties of bioceramic, coral and processed bone graft substitutes. Biomaterials 1995;16:1181-5.

14. Klawitter J, Hulbert S. Application of porous ceramics for the attachment of load bearing orthopedic applications. J Biomed Mat Res Symp 1971;2:161-230.

15. Eldridge JD, Cunningham JL, Samuels A, et al. Glass ionomer as an expander of allograft in revision arthroplasty of the hip. Biomaterials 2003;24:499-508.

16. Edberg E. Some experiences of filling osseous cavities with plaster. Acta Chir Scand 1930;67:313-19

17. Bell W. Resorption characteristics of bone and bone substitutes. Oral Surg Oral Med Oral Pathol 1964;17:650-7.

18. Ransford A, Morley T, Edgar M, et al. Synthetic porous ceramic compared with autograft in scoliosis surgery: a prospective, randomized study of 341 patients. J Bone Joint Surg [Br] 1998;80-B:13-18.

19. Hanft J, Sprinkle R, Surprenant M, Werd M. Implantable bone substitute materials. Clin Podiatr Med Surg 1995;12:437-55.

20. Blom AW, Grimm B, Miles AW, Cunningham JL, Learmonth ID. Subsidence in impaction grafting: the effect of adding a ceramic bone graft extender to bone. Proc Instr Mech Eng H 2002;216:265-70.

21. Gruen T, McNiece G, Amstutz H. "Modes of failure" of cemented stem-type femoral components: a radiographic analysis of loosening. Clin Orthop 1979;141:17-27.

22. Bergmann G, Siraky J, Rohlman A, Koelbel R. A comparison of hip joint forces in sheep, dog and man. J Biomech 1984;17:907-21

23. Jarcho M. Calcium phosphate ceramics as hard tissue prosthetics. Clin Orthop 1981; 157:259-78

24. Shimazaki K, Mooney V. Comparative study of porous hydroxyapatite and calcium phosphate as bone substitute. J Orthop Res 1985;3:301-10. 